\title{
Journal of Synchrotron
} Radiation

Volume 21 (2014)

Supporting information for article:

Development of a microsecond X-ray protein footprinting facility at the Advanced Light Source

Sayan Gupta, Richard Celestre, Christopher J. Petzold, Mark R. Chance and Corie Ralston 
Figure S1 Radiolysis of water and the timescale of sequence of events reproduced from Liljenzin, J., Radiation Effects on Matter, in Radiochemistry and Nuclear Chemistry, 2002, Butterworth-Heinemann.

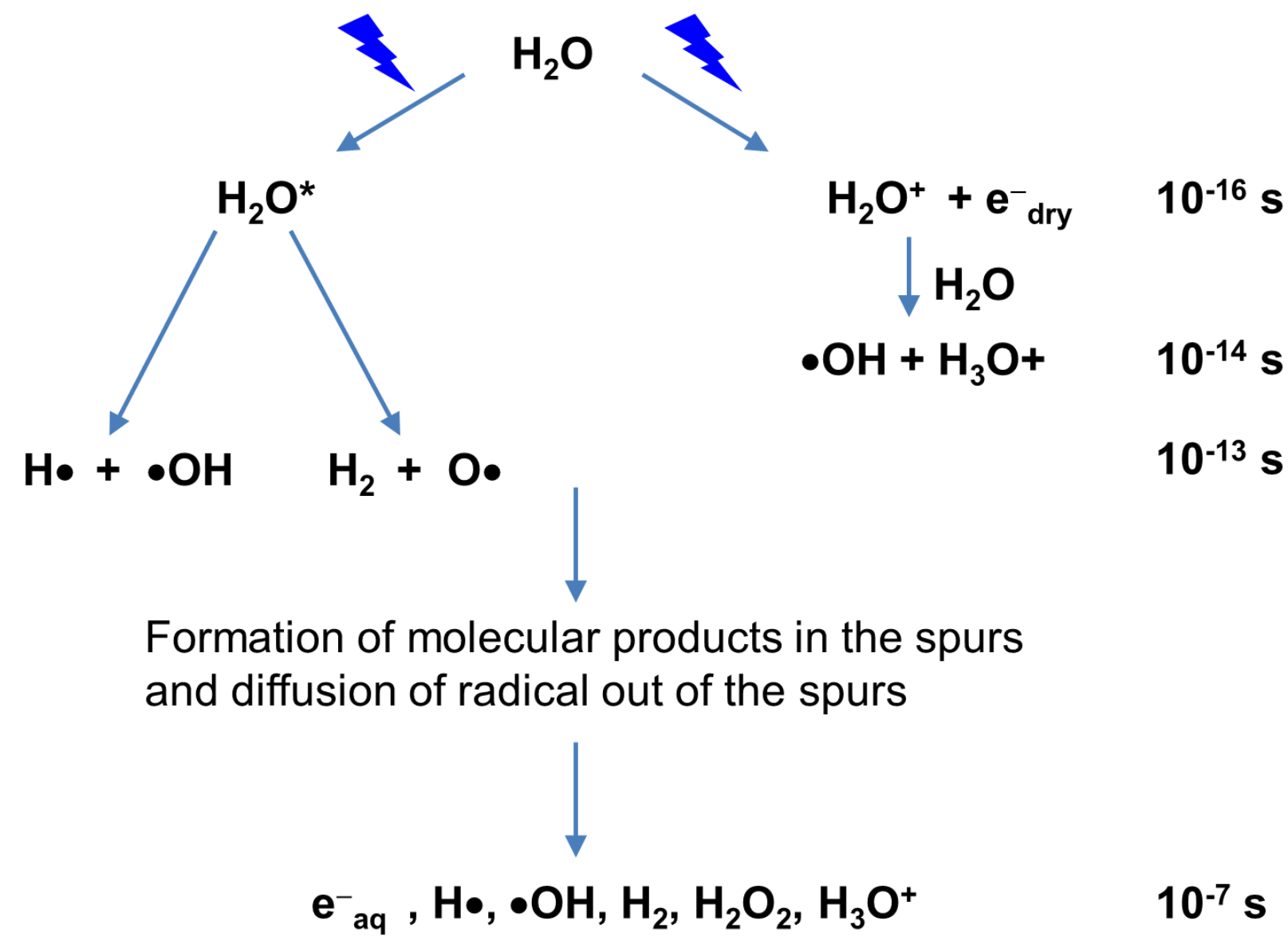


Figure S2 List of recombination reactions during the spur diffusion process, which lead to the formation of molecular or secondary radical products. The scheme is adapted from Liljenzin, J., Radiation Effects on Matter, in Radiochemistry and Nuclear Chemistry, 2002, Butterworth-Heinemann.

$$
\begin{gathered}
\mathrm{e}_{\mathrm{aq}^{-}}+\mathrm{e}_{\mathrm{aq}^{-}}=\mathrm{H}_{2}+2 \mathrm{OH}^{-} \\
\mathrm{e}^{-}{ }^{-}+\bullet \mathrm{OH}=\mathrm{OH}^{-} \\
\mathrm{e}_{\mathrm{aq}}{ }^{-}+\mathrm{H}_{3} \mathrm{O}^{+}=\mathrm{H} \bullet+\mathrm{H}_{2} \mathrm{O} \\
\mathrm{e}_{\mathrm{aq}}{ }^{-}+\mathrm{O}_{2}=\bullet \mathrm{O}_{2}^{-} \\
\mathrm{H} \bullet+\mathrm{H}^{-}=\mathrm{H}_{2} \\
\mathrm{H} \bullet+\mathrm{O}_{2}=\bullet \mathrm{HO}_{2} \\
\bullet \mathrm{OH}+\bullet \mathrm{OH}^{-} \mathrm{H}_{2} \mathrm{O}_{2} \\
\bullet \mathrm{OH}+\mathrm{H}^{\bullet}=\mathrm{H}_{2} \mathrm{O} \\
\mathrm{H}_{3} \mathrm{O}^{+}+\mathrm{OH}^{-}=\mathrm{H}_{2} \mathrm{O}
\end{gathered}
$$


Figure S3 Molecular oxygen is necessary for radiolytic modification<smiles>CC(=O)C(Cc1ccccc1)N(C)CCCO</smiles>

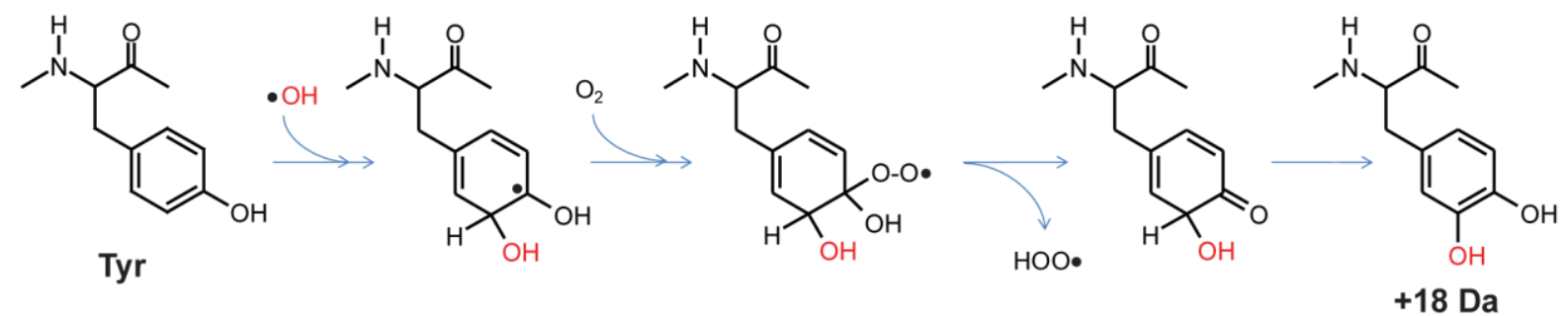

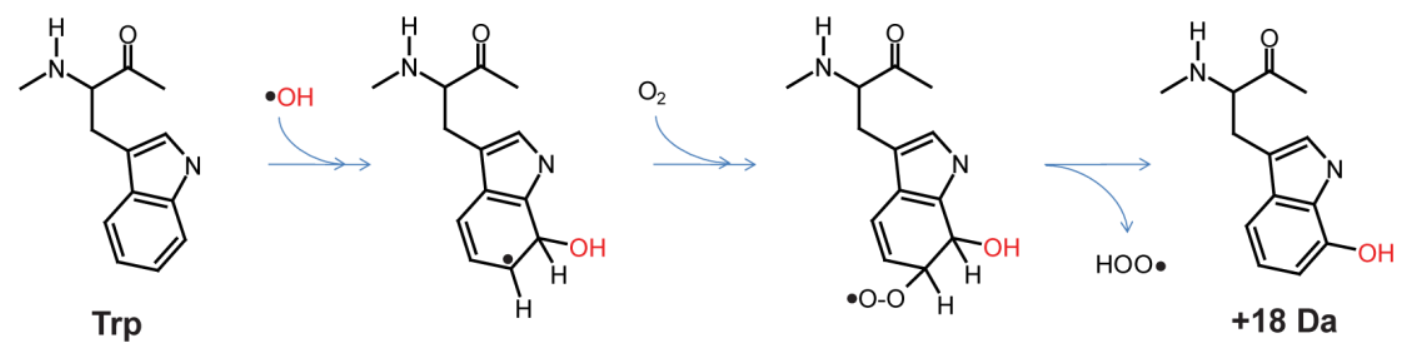<smiles>CNC(CCSC)C(CCS(C)=O)N(C)NC(C)=O</smiles>

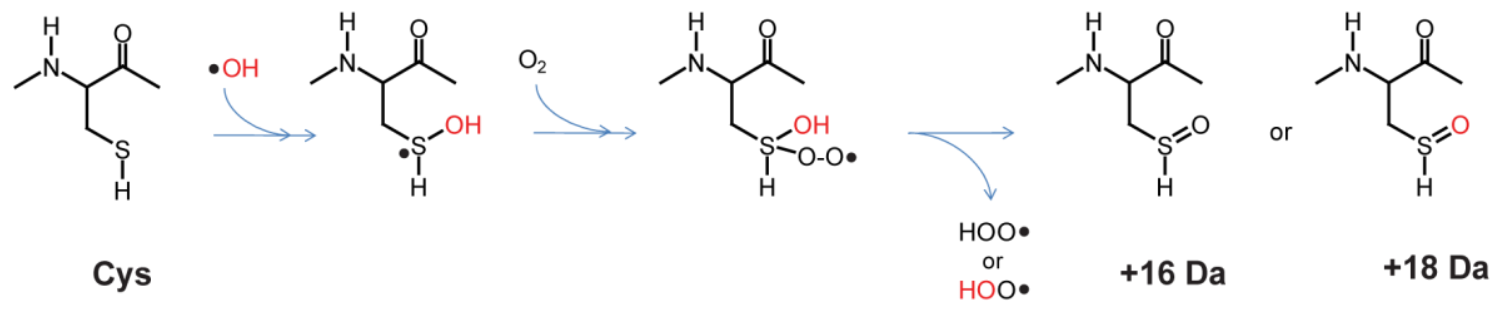


Figure S4 Alexa dose response of the buffer used for mmcpn sample exposure. The solid lines represent single exponential fits with rate constants $k=2061 \mathrm{sec}^{-1}$ (black) and $740 \mathrm{sec}^{-1}$ (red) for the buffers $10 \mathrm{mM}$ Na-Phosphate $\mathrm{pH} 7$ and $10 \mathrm{mM}$ sodium cacodylate containing 1mM TCEP, 1mM ATP, $5 \%$ glycerol and $120 \mathrm{mM} \mathrm{NaCl}$.

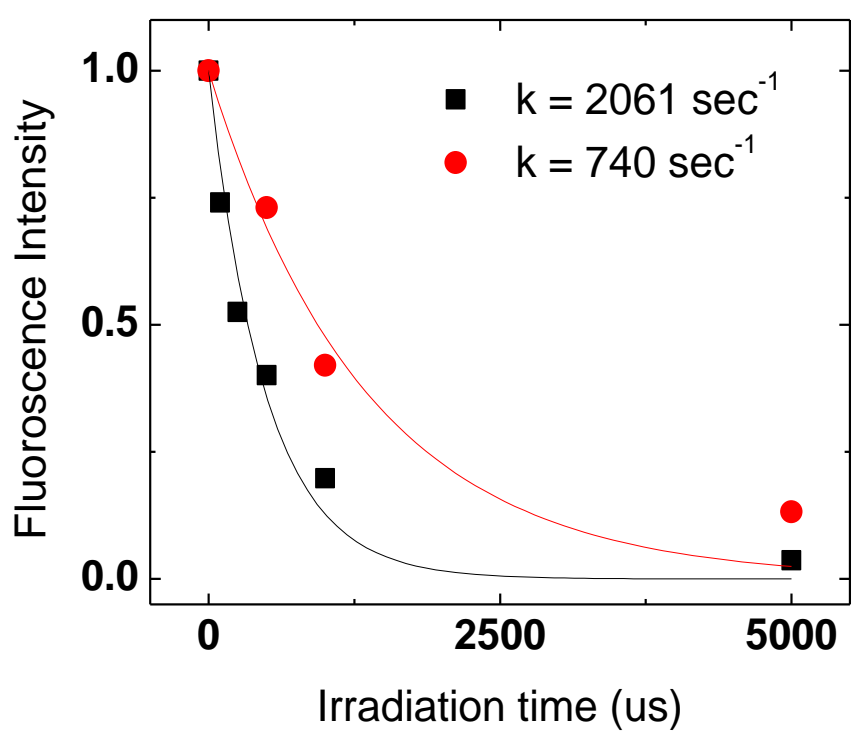

